\title{
RESEARCH ARTICE
}

\section{Determining the best practices for remote experiential rotations}

\author{
Catherine Zhu (D), Thomas E R Brown \\ Leslie Dan Faculty of Pharmacy, University of Toronto, Toronto, Canada
}

\author{
Keywords \\ Pharmacy \\ Preceptorship \\ Remote \\ Rotation \\ Virtual \\ Correspondence \\ Catherine Zhu \& Thomas Brown \\ Leslie Dan Faculty of Pharmacy \\ University of Toronto \\ Room 702 \\ 144 College Street \\ Toronto \\ Ontario \\ Canada \\ M5S 3M2 \\ cat.zhu@mail.utoronto.ca
}

\begin{abstract}
Introduction: During the COVID-19 pandemic, clinical sites have closed their doors to student placements, leading to the implementation of remote rotations. The purpose was to determine best practices for distance preceptorship from the student's perspective. Methods: A survey was sent to the pharmacy students at the Leslie Dan Faculty of Pharmacy who have completed at least one remote rotation. Results: Forty-eight out of 121 students (39\%) completed the survey. It was found that $83 \%$ of the students were motivated during the start of their rotations, while $48 \%$ remained motivated throughout. Students who remained motivated had clear expectations set from the beginning, felt comfortable communicating issues regarding their assigned work with their preceptor, had similar rapport with remote preceptors as with in-person preceptors, had a preceptor who is always available for questions, and had a work environment free of distractions. Discussion:There are numerous best practices students and preceptors can utilise during a remote rotation to help students remain motivated. Preceptors and students should work together so that students remain motivated throughout their rotation. Setting expectations, having good communication, getting to know their preceptor, and having a work environment free of distractions are key factors for conducting a remote rotation.
\end{abstract}

\section{Introduction}

Preceptorship is described as the pairing of a student with a clinician with experience in a clinical area (Myrick et al., 2011). Preceptorship requires following specific learning objectives in hopes that the student will become a competent learner by the end of their rotation; thus, preceptors play a pivotal role in the education of health science students such as pharmacy students (Barker, 2005). The majority of preceptor-student relationships are done in person at a clinical site. During the time of the COVID-19 pandemic, many clinical sites have closed their doors for unpaid student placements, leaving students unable to complete their clinical rotations on-site. Toronto, Canada and its surrounding cities, where the majority of clinical rotations are held for students at the University of Toronto, have been labelled a COVID-19 hotspot, leading to tighter restrictions. At the time the Leslie Dan Faculty of Pharmacy chose to move their rotations online, restrictions included the closure of non-essential workplaces, restaurants, gyms, and outdoor amenities in parks and recreational areas, as well as limiting indoor gatherings to those in the same household 
(The Government of Ontario, 2020). Pharmacy students at the Leslie Dan Faculty of Pharmacy are required to complete seven five-week block Advanced Pharmacy Practice Experiences (APPE) in their fourth year before graduation; however, during this time, the faculty has cancelled all on-site APPE rotations for the first two blocks and moved them online. There has been ample research on how to build good preceptors; however, the majority of this research has been done on in-person preceptorships, leaving a gap in knowledge about virtual, remote preceptorships. One method of measuring successful preceptorship is to determine students' attitudes toward their rotation. Studies that do look at virtual preceptorship lack information on how students perceive their virtual rotations.

There have been many technological advances in healthcare in recent years, and pharmacy schools have been finding ways to implement these novel learning strategies into their curriculum. Although virtual learning may be the way of the future, it may not be beneficial to some students. A study by Al-Dahir et al. (2014) randomly assigned fourth-year pharmacy students to either completing an online patient case through a virtual platform or a small-group discussion. They found that the traditional small-group discussion group experienced a greater improvement in post-experience test scores than the online patient case group. They suggested this improvement was due to the fact that pharmacy students are more accustomed to this style of learning; however, this paper was published in 2014, and many pharmacy schools have adopted virtual patient cases into their curriculum. Although this study involved methods to conduct a virtual experiential rotation in pharmacy, it did not involve preceptorship and its effect on students. Many studies have also been conducted on e-learning and blended learning in a classroom environment for health science students; however, preceptorship does not occur in these settings. Rowe, Frantz \& Bozalek (2012) reviewed articles discussing the integration of face-to-face and online interaction in the clinical education of healthcare students in an education style known as blended learning. They found few high-quality articles examining this topic; however, the consensus was that the addition of online learning to traditional approaches of teaching has the potential to improve clinical skills. Overall, these studies and reviews on virtual learning concluded that the integration of some online learning methods is promising for building future healthcare professionals; however, there is a lack of understanding on how preceptors can play an effective role in online education and students attitudes about their remote preceptorship.
During the COVID-19 pandemic, social distancing measures have been enforced by governments, causing many businesses to move their workforce online and leaving employees to work from home. This allowed the creation of many online resources for staying productive while working from home. These tips include creating a designated workspace, frequently communicating with co-workers and managers, maintaining a schedule, and having the proper IT support (Austin, 2020; Borsellino, 2020; Duffy, 2020). Recommendations for how supervisors and managers can effectively manage their remote employees are also available, and these include setting clear expectations, establishing daily check-ins, offering encouragement, and providing several modes of communication (Forbes Coaches Council, 2018; Larson, Vroman \& Makarius, 2020). With these suggestions in mind, the authors conducted a study on the effects of certain domains involving the student's experience with their remote rotation in order to understand how preceptors can help optimise the student's experience.

\section{Purpose and objectives}

The purpose of this study was to determine the best practices for remote preceptorship from the student's perspective for pharmacy students on their APPE rotations. The objectives were to develop a list of best practices and determine if these best practices helped with experiential rotations from the student's perspective.

\section{Methods}

This study was a cross-sectional survey of pharmacy students of a Doctor of Pharmacy programme who have completed at least one remote APPE rotation. The survey consisted of an online questionnaire. This study was approved by the Leslie Dan Faculty of Pharmacy's Undergraduate Research Ethics Review Committee (study ID 2020-002). There were 121 students who completed a remote APPE rotation in the first five-week block which started on 4th May 2020, and those students were sent the survey.

A survey of best practices for remote learning was developed (Appendix A). To develop the survey, a review of the literature was conducted, using Medline to identify articles relating to the authors' subject area. Search terms included preceptorship, precept, preceptor, distant education, and remote education. Articles were considered if they examined preceptorship in distant education with health sciences students, such as 
pharmacy, medicine, and nursing students. Searches on the Google search engine were also conducted to identify online resources for working from home and managing employees from home. Based on the literature search and online resources, the survey included five domains: 1) Expectations; 2) Communication, Relationship, and Availability; 3) Routine, Environment, and Confidentiality; 4) Resources and IT support and 5) Motivation and Satisfaction. The survey was pre-tested and reviewed for readability by two APPE students and two faculty members who were independent from this study and had experience with survey development. Revisions of the survey based on comments from the pre-test were made prior to the final version being sent to the students. The survey was made on Google Forms, and responses were anonymous. There were no questions that were mandatory for students to answer in order to complete the survey. Information regarding confidentiality, the purpose of the study, risks, and benefits, were provided before students started the survey. Completing the survey implied that the student had given consent. Students could request withdrawal of consent during the time of the survey or after they submitted at any time. Students received the survey at the end of the first APPE block via e-mail, and they were requested to complete the survey within one week.

Questions including the participant's sex, rotation type, previous experience with remote rotations, and previous experience with in-person preceptors were collected. The following types of questions for each domain were collected:

Expectations: 4 questions total - one rating question (Likert scale), two yes/no questions, and one open-ended question.

Communication, Relationship, and Availability: Seventeen questions total - ten rating questions (Likert scale), one yes/no question, two check all that apply questions, three choose one that applies question, and one open-ended question.

Routine, Environment, and Confidentiality: Nine questions total - four rating questions (Likert scale), four yes/no questions, and one open-ended question.

Resources and IT Support: Six questions total - three rating questions (Likert scale), one yes/no question, one check all that apply question, and one open-ended question.

Motivation and Satisfaction: Eight questions total - five rating questions (Likert scale), two check all that apply questions, and one open-ended question.
Descriptive statistic tools with percentages were used to report the authors' findings for questions, including the participant's sex, rotation type, previous experience with remote rotations, previous experience with in-person preceptors, and modes of communication. Study groups were determined based on the level of motivation at the beginning of a student's remote APPE rotation and their motivation level throughout their remote APPE rotation. If students were motivated at the start and remained motivated throughout, they were placed in the positive outcome group. If students were either motivated at the start and then dropped to a neutral level of motivation or became unmotivated, were neutral or unmotivated at the start and remained at the same level, or if they were unmotivated at the start and only increased their motivation level to neutral, they were placed in the negative outcome group. Likert scale data were collapsed into three categories of data (those who strongly disagree/disagree, are neutral, and those who strongly agree/agree), and individual Likert scale questions were compared to students' motivation levels during their remote APPE rotation using the Mann-Whitney $U$ test. Binomial data from the closed-ended questions were compared using Fisher's Exact test or Chi-Square statistics. Open-ended free form questions were analysed qualitatively for themes.

\section{Results}

Out of 121 students who were sent the survey, 48 students completed the survey, resulting in a $39 \%$ response rate. The majority of respondents previously had experienced an in-person preceptorship, with 92\% responding that they have had one (Table I). When surveyed, $83 \%$ of students reported being motivated at the start of their rotations, while $48 \%$ remained motivated throughout $(p=0.01)$. There were 23 students in the positive outcome group and 25 students in the negative outcome group (Table I). The majority of students had scheduled meetings with their preceptor a few times weekly (56\%) and almost a third (29\%) had daily scheduled meetings (Table I); however, the majority of students (69\%) had impromptu meetings between the scheduled meetings over video conference or phone call (Table I). There were $67 \%$ of students who had access to confidential information, such as patient information (Table I). Overall, $81 \%$ of students strongly agreed or agreed that their remote APPE rotation was a successful learning opportunity (Table I). More non-direct patient care rotations were done over direct patient care 
rotations, with the majority of respondents participating in research, education and/or pharmaceutical industry rotations (Table II). Communication with their preceptor via e-mail (93.8\%) and video conferencing (95.8\%) were the most popular modes of communication, with many students and preceptors choosing to use Zoom and/or Microsoft Teams (Table III).

Table I: Demographics of students who participated in the survey on best practices for remote preceptorships $(\mathrm{N}=48)$

\begin{tabular}{|c|c|}
\hline & No (\%) \\
\hline \multicolumn{2}{|l|}{ Gender } \\
\hline Male & $11(23)$ \\
\hline Female & $37(77)$ \\
\hline \multicolumn{2}{|c|}{ Past in-person experiential preceptorship experience } \\
\hline Yes & $44(92)$ \\
\hline No & $4(8)$ \\
\hline \multicolumn{2}{|c|}{ Motivated at the start of their rotation } \\
\hline Strongly agree/agree & $40(83)$ \\
\hline Neutral & $3(6)$ \\
\hline Strongly disagree/disagree & $5(11)$ \\
\hline \multicolumn{2}{|c|}{ Motivated throughout their rotation } \\
\hline Strongly agree/agree & $23(48)$ \\
\hline Neutral & $18(38)$ \\
\hline Strongly disagree/disagree & $7(14)$ \\
\hline \multicolumn{2}{|c|}{ Frequency of preceptor meetings on a scheduled basis } \\
\hline More than once daily & $0(0)$ \\
\hline Once daily & $14(29)$ \\
\hline Few times weekly & $25(56)$ \\
\hline Once weekly & $7(15)$ \\
\hline \multicolumn{2}{|c|}{$\begin{array}{l}\text { Frequency of impromptu meeting times via video conferencing } \\
\text { platform or phone call }\end{array}$} \\
\hline Never & $15(31)$ \\
\hline 1-2 times between meetings & $27(56)$ \\
\hline 3-5 times between meetings & $6(13)$ \\
\hline \multicolumn{2}{|c|}{ Frequency of meetings was sufficient } \\
\hline Wanted less meetings & $4(8)$ \\
\hline No change & $40(84)$ \\
\hline Wanted more meetings & $4(8)$ \\
\hline \multicolumn{2}{|c|}{ Had access to confidential information } \\
\hline Yes & $32(67)$ \\
\hline No & $16(33)$ \\
\hline \multicolumn{2}{|c|}{$\begin{array}{l}\text { Believed their remote APPE rotation was a successful learning } \\
\text { opportunity }\end{array}$} \\
\hline Strongly agree/agree & $39(81)$ \\
\hline Neutral & $8(17)$ \\
\hline Strongly disagree/disagree & $1(2)$ \\
\hline
\end{tabular}

Table II: Types of remote APPE rotation students participated in $(\mathrm{N}=48)$

\begin{tabular}{lc}
\hline & No (\%) \\
\hline Education & $11(22.9)$ \\
Research & $21(43.8)$ \\
Pharmaceutical industry & $11(22.9)$ \\
Community & $7(14.6)$ \\
Leadership and management & $2(4.2)$ \\
Direct patient care & $2(4.2)$ \\
Other & $3(6.3)$ \\
\hline
\end{tabular}

Students could choose more than one option

Table III: Modes of communication used by students to communicate with their remote preceptors $(\mathrm{N}=48)$

\begin{tabular}{lc}
\hline & No (\%) \\
\hline Video conference & $45(93.8)$ \\
E-mail & $46(95.8)$ \\
Text message & $22(45.8)$ \\
Phone call & $23(47.9)$ \\
Online chat & $16(33.3)$ \\
Other & $1(2.1)$ \\
\hline
\end{tabular}

Students could choose more than one option

Table IV. Student responses to yes/no questions from survey on best practices for remote preceptorships

\begin{tabular}{|c|c|c|c|c|}
\hline Survey statement & $\begin{array}{l}\text { Respondents } \\
\text { (\%) }\end{array}$ & $\begin{array}{l}\text { Yes } \\
\text { (\%) }\end{array}$ & $\begin{array}{l}\text { No } \\
\text { (\%) }\end{array}$ & $\begin{array}{c}p- \\
\text { value }\end{array}$ \\
\hline $\begin{array}{l}\text { My preceptor and I set expectations } \\
\text { collaboratively. }\end{array}$ & $\begin{array}{c}47 \\
(98)\end{array}$ & $\begin{array}{c}44 \\
(94)\end{array}$ & $\begin{array}{c}3 \\
(6)\end{array}$ & $1^{\mathrm{a}}$ \\
\hline $\begin{array}{l}\text { My preceptor and I had set meeting } \\
\text { times through a video conferencing } \\
\text { platform or phone call. }\end{array}$ & $\begin{array}{c}48 \\
(100)\end{array}$ & $\begin{array}{c}44 \\
(92)\end{array}$ & $\begin{array}{c}4 \\
(8)\end{array}$ & $0.33^{\mathrm{a}}$ \\
\hline $\begin{array}{l}\text { My preceptor allowed me to create } \\
\text { my own hours and schedule. }\end{array}$ & $\begin{array}{c}48 \\
(100)\end{array}$ & $\begin{array}{c}41 \\
(85)\end{array}$ & $\begin{array}{c}7 \\
(15)\end{array}$ & $1^{\mathrm{a}}$ \\
\hline $\begin{array}{l}\text { I had set hours, either set by } \\
\text { preceptor or myself, during the day to } \\
\text { complete my assigned work. }\end{array}$ & $\begin{array}{c}48 \\
(100)\end{array}$ & $\begin{array}{c}31 \\
(67)\end{array}$ & $\begin{array}{c}16 \\
(33)\end{array}$ & $0.84^{b}$ \\
\hline
\end{tabular}

aFisher's Exact Test was used to determine significance between the two student groups ${ }^{b}$ Chi Square Test was used to determine significance between the two student groups Significance level set at $p \leq 0.05$

Results of the analysis of Yes/No and Likert scale questions can be found in Table IV and V. Students who had clear expectations set from the beginning of their remote rotation were significantly more likely to remain motivated throughout their rotation than when expectations were not clear $(p=0.05)$; however, setting 
Table V: Student responses to 5-point Likert scale questions from survey on best practices for remote preceptorships

\begin{tabular}{|c|c|c|c|c|}
\hline Survey statement & $\begin{array}{l}\text { Positive outcome } \\
\text { median (IQR) }\end{array}$ & $\begin{array}{l}\text { Negative outcome } \\
\text { median (IQR) }\end{array}$ & $Z$ & $\begin{array}{c}p- \\
\text { value }\end{array}$ \\
\hline The expectations set were clear from the beginning of my rotation(s). & $3(3-3)$ & $3(2-3)$ & -2.0 & $0.05^{*}$ \\
\hline The mode(s) of communication I used with my preceptor was/were adequate and easy to navigate. & $3(3-3)$ & $3(3-3)$ & -1.3 & 0.17 \\
\hline Our meetings were productive. & $3(3-3)$ & $3(3-3)$ & -1.6 & 0.10 \\
\hline I felt comfortable communicating any issues I had with my assigned work to my preceptor. & $3(3-3)$ & $3(2-3)$ & -2.9 & $0.003^{*}$ \\
\hline My preceptor provided me with ongoing feedback and constructive criticism. & $3(3-3)$ & $3(2-3)$ & -1.5 & 0.14 \\
\hline My preceptor made an effort to get to know me. & $3(3-3)$ & $3(2-3)$ & -1.5 & 0.14 \\
\hline I had a good relationship with my preceptor. & $3(3-3)$ & $3(3-3)$ & -1.0 & 0.34 \\
\hline $\begin{array}{l}\text { I was able to build a similar rapport with my remote preceptor as with my in-person preceptor(s) in } \\
\text { the past. }\end{array}$ & $3(2-3)$ & $2(1-3)$ & -2.7 & $0.007^{*}$ \\
\hline My preceptor was always available to answer any questions. & $3(3-3)$ & $3(2-3)$ & -2.2 & $0.03^{*}$ \\
\hline I had many competing priorities while completing my remote APPE rotation(s). & $2(2-3)$ & $1(1-3)$ & -1.2 & 0.29 \\
\hline $\begin{array}{l}\text { I had more difficulty prioritising my work during my remote rotation(s) than during my in-person } \\
\text { rotation(s). }\end{array}$ & $2(1-3)$ & $3(2-3)$ & 1.7 & $0.08^{*}$ \\
\hline Having flexibility to create my own hours and schedule was beneficial. & $3(3-3)$ & $3(2-3)$ & -1.6 & 0.12 \\
\hline I was able to maintain a daily routine. & $3(2-3)$ & $3(2-3)$ & -1.2 & 0.24 \\
\hline The resources I needed were easily accessible for me. & $3(3-3)$ & $3(2-3)$ & -1.6 & 0.11 \\
\hline My Internet connection was adequate. & $3(3-3)$ & $3(2-3)$ & -1.0 & 0.30 \\
\hline I was able to utilise appropriate IT support, if needed (i.e. from the Faculty, third party companies). & $2(2-3)$ & $2(2-2)$ & -1.4 & 0.15 \\
\hline I had a comfortable work environment. & $3(3-3)$ & $3(2-3)$ & -1.6 & 0.11 \\
\hline My work environment was free from any distractions. & $3(2-3)$ & $1(1-3)$ & -2.4 & $0.02 *$ \\
\hline My remote rotation(s) was more stressful than my past in-person rotation(s). & $2(1-3)$ & $2(1-3)$ & -0.3 & 0.77 \\
\hline
\end{tabular}

Mann-Whitney $\mathrm{U}$ test was used to compare differences in survey responses for 5-point Likert scale questions (1=strongly disagree, $5=$ strongly agree) between the two student groups. Responses were collapsed and analyzed into three groups, where $1=$ strongly disagree/disagree, $2=$ neutral, and $3=$ strongly agree/agree. Significance level set at $p \leq 0.05$

*significant association with motivation level throughout rotation

Table VI: Factors that contributed to students' motivation during their remote APPE rotation ( $N=48$ )

\begin{tabular}{lc}
\hline & No (\%) \\
\hline Good communication with my preceptor & $39(81.3)$ \\
Set meeting times with my preceptor & $39(81.3)$ \\
Good relationship with my preceptor & $35(72.9)$ \\
Set expectations & $33(68.8)$ \\
Comfortable work environment & $31(64.6)$ \\
Preceptor availability & $29(60.4)$ \\
Daily routine & $26(54.2)$ \\
Stable Internet connection & $25(52.1)$ \\
Set work hours & $20(41.7)$ \\
Abundant resources available & $18(37.5)$ \\
Other & $2(4.2)$ \\
\hline Students could choose more than one option &
\end{tabular}

Students could choose more than one option

expectations collaboratively with their preceptor did not result in students remaining motivated $(p=1.00)$. The domain of Communication, Relationship, and Availability
Table VII: Factors that reduced students' motivation during their remote APPE rotation $(\mathrm{N}=48)$

\begin{tabular}{lc}
\hline & No (\%) \\
\hline Lack of daily routine & $18(45)$ \\
Lack of set work hours & $15(37.5)$ \\
Lack of resources & $9(22.5)$ \\
Mismatched expectations between my preceptor and myself & $8(20)$ \\
Poor Internet connection & $8(20)$ \\
Infrequent meetings with my preceptor & $7(17.5)$ \\
Poor communication with my preceptor & $6(15)$ \\
Uncomfortable work environment & $6(15)$ \\
Lack of expectations & $5(12.5)$ \\
Lack of preceptor availability & $1(2.5)$ \\
Poor relationship with my preceptor & $0(0)$ \\
Other & $12(30)$ \\
\hline
\end{tabular}

Students could choose more than one option.

had three out of ten practices that were associated with student's motivation levels. Students who remained 
motivated were also significantly more comfortable communicating any issues they had regarding their assigned work with their preceptor $(p=0.003)$. Students who had previous experience with an in-person preceptorship were significantly more likely to remain motivated if they were able to build a similar rapport with their remote preceptor as with their in-person preceptor in the past $(p=0.007)$. Remote preceptors who were always available to answer questions, allowed students to be significantly more likely to remain motivated than preceptors who were not $(p=0.03)$. For the domain of Routine, Environment, and Confidentiality, work environments that were free from distractions also allowed students to be significantly more likely to remain motivated ( $p=0.01$ ); however, having a comfortable work environment did not affect motivation levels $(p=0.11)$. Questions pertaining to the domain of Resources and IT Support did not affect motivation levels. Students did not consider having easily accessible resources, adequate Internet connection, or appropriate IT support as best practices for preceptorship. Students noted that the top factors that contributed to their motivation during their remote APPE rotation were good communication with their preceptor $(81.3 \%)$, having set meeting times with their preceptor $(81.3 \%)$, and having a good relationship with their preceptor $(72.9 \%$, Table VI). Top factors that reduced students' motivation were a lack of daily routine (45\%), a lack of set work hours (37.5\%), and a lack of preceptor availability (22.5\%, Table VII).

Table VIII: Themes of relevant comments to free-form questions ( $\mathrm{N}=18$ )

\begin{tabular}{lc}
\hline Theme of comment & $\begin{array}{c}\text { Number of students } \\
\text { making the comment }\end{array}$ \\
\hline Expectations given by preceptor & 3 \\
Clarification on tasks & 3 \\
Availability and timely response & 4 \\
Lack of structure & 3 \\
Inadequate resources & 2
\end{tabular}

Students could mention multiple themes in one response.

Certain themes were brought up by students when asked to give a free form response (Table VIII). Expectations given by their preceptor were mentioned by a few students, including one student who said 'make objectives/ expectations clear at the beginning instead of relying on our learning objectives because we really didn't know what we were supposed to be doing' when asked about what their preceptor could have improved regarding communication. Along with unclear expectations, many students had trouble clarifying what their preceptor wanted from an assigned task. One student said that their preceptor 'wasn't clear about what it was he wanted his students to do (i.e., would send us an article to read and then a week later ask why we didn't critically appraise it when there was no direct expectation set)'. Availability and timely responses from preceptors were other themes mentioned by students. Regarding how their preceptor could have improved the communication, one student mentioned 'in between video meetings, questions and documents sent for review were not always promptly replied to' and another said 'more prompt review and feedback of materials sent to the preceptor would be appreciated'.

\section{Discussion}

This study confirmed that there are numerous best practices students and preceptors can utilise during a remote experiential rotation to help students remain motivated. Setting clear expectations from the very beginning of the remote rotation can be a catalyst for other best practices to occur. Providing clear communication from the start will allow the student to feel more comfortable speaking to the preceptor if any issues arise during the rotation. The nature of remote rotations allows for less opportunity for communication between the student and their preceptor. In an in-person rotation, students are in close physical proximity to their preceptor, allowing for more guidance and clarification on their assigned work. During remote rotations, many students only met virtually with their preceptor, either once daily or even once weekly. In the context of online learning as a whole, having consistent patterns of interaction as well as immediate accessibility to the instructor has been shown to improve the relationship between instructors and their students (Baker, 2010). The decreased opportunity for communication during remote rotations requires both parties to put more effort into opening the line of communication. Results of this study were similar to those found in a study done by Rand \& Pajarillo (2015) who looked at virtual preceptorship and mentorship through distant education for the Doctor of Nursing Practice Students. They highlighted several themes that were mentioned by virtual preceptors, with one major finding being that building a strong professional and social connection was important for successful preceptorship (Rand \& Pajarillo, 2015). 
Creating a workspace free from distractions is another best practice that students can implement themselves. For an in-person rotation, students most likely would have a designated workspace at their rotation site to help them focus on their work. There are no family members or pets around, which are factors that lead to distractions while working from home. Students are also less likely to be on their phones or do other distracting tasks while they are in close proximity to their preceptor. It is important that students try to reduce distractions that they usually would not have during an in-person rotation; however, not all students have the luxury of having a distraction-free workspace or adequate Internet connection due to socioeconomic inequalities.

During their time at the Leslie Dan Faculty of Pharmacy, pharmacy students are required to complete direct patient care rotations, which either involves a community or hospital setting, prior to their APPE rotations. Students on their APPE rotations can complete non-direct patient care rotations, which may involve research, education, or pharmaceutical industry projects. The majority of respondents completed a non-direct patient care rotation, which for many students, is the first time they have been exposed to these types of projects. Lack of clarification and expectations during their rotations were themes many students mentioned, regardless of their rotation type. Preceptors should be aware that their student may not have any experience doing tasks they may find trivial, such as performing a literature search or doing statistical analyses. For online instructors, setting clear expectations by providing examples of past assignments has been suggested as a method to improve learner's satisfaction since it provides concrete ideas for succeeding in the course (Dennen, Aubteen, \& Smith, 2007). The responsibility should not solely lie with the preceptor. Students must realise their gaps in knowledge and take the initiative to ask their preceptor for more guidance since students who are aware of their needs tend to have greater success in online learning environments (Berenson, Boyles \& Weaver, 2008). Faculties can also ease the situation by encouraging preceptors to be clearer on their expectations.

\section{Limitations}

Since the majority of respondents completed a non-direct patient care rotation remotely $(96 \%)$, these findings may not be applicable to direct patient care remote rotations.
The clinical competencies and expectations are different between the two types of rotations, and results may differ based on the rotation type. The study involved an optional survey and self-reported data, which may contribute to different types of biases. Selection bias and non-response bias may have occurred since students had the choice of whether or not to complete the survey. Responses and attitudes are also subjective based on the student. Every learner has different needs; some students may find motivation through building a social connection with their preceptor, but other students may feel uncomfortable speaking to their preceptor about anything but their assigned work. This is highlighted by a study done by Myrick et al. (2011), where they designed an online learning space to help support preceptors in order to enhance the quality of preceptorship. One of the modules taught the preceptors about the importance of catering to different learning styles of students, which brought awareness to preceptors on the importance of how preceptorship can be influenced by the student's learning style (Myrick et al., 2011). Another limitation is the sample size. Although the authors achieved a typical response rate for an online survey, the sample size was small, meaning results may differ if the sample size was larger (Nulty, 2008). External factors could have played a role in a student's motivation level. During the COVID-19 pandemic, people in general were less motivated to do everyday tasks (Brooks et al., 2020). With the results of this study, the authors hope these best practices can help students remain motivated during this difficult time.

\section{Conclusion}

Preceptors play an important role in the development of future healthcare professionals, including pharmacists. During the COVID-19 pandemic, the Leslie Dan Faculty of Pharmacy has had to move their rotations online, and students and preceptors must work from home. From this study, the authors have found that setting clear expectations from the beginning of the rotation, creating a space where students feel comfortable to communicate any issues they have regarding their assigned work with their preceptor, building a similar rapport with remote preceptors as with in-person preceptors, having a preceptor who is always available to answer questions, and having a work environment free from any distractions are the best practices for conducting a remote experiential rotation in order to remain motivated from a student's perspective. 


\section{References}

Austin, P.L. (2020). 5 Tips for Staying Productive While You're Working From Home. Available at: https://time.com/5801725/ work-from-home-remote-tips/

Al-Dahir, S., Bryant, K., Kennedy, K.B., \& Robinson, D.S. (2014). Online Virtual-Patient Cases Versus Traditional Problem-Based Learning in Advanced Pharmacy Practice Experiences. American Journal of Pharmaceutical Education, 78(4). https://doi.org/ $\underline{10.5688 / a j p e 78476}$

Baker, C. (2010). The Impact of Instructor Immediacy and Presence for Online Student Affective Learning, Cognition, and Motivation. Journal of Educators, 7(1). https://doi.org/10.9743/j eo.2010.1.2

Barker, E.R. (2005). Mentoring - A complex relationship. Journal of the American Academy of Nurse Practitioners, 18(2), 56-61. https://doi.org/10.1111/i.1745-7599.2006.00102.x

Berenson, R., Boyles, G., \& Weaver, A. (2008). Emotional Intelligence as a Predictor of Success in Online Learning. International Review of Research in Open and Distance Learning, 9(2), 1-16. https://doi.org/10.19173/irrodl.v9i2.385

Borsellino, R. (2020). 7 Essential Tips for Working From Home During the Coronavirus Pandemic. Available at: https://www.the muse.com/advice/coronavirus-work-from-home-tips

Brooks, S.K., Webster. R.K., Smith, L.E., Woodland, L., Wessely, S., Greenberg, N., \& Rubin, G.R. (2020). The psychological impact of quarantine and how to reduce it: rapid review of the evidence. Lancet, 395(10227), 912-920. https://doi.org/10.1016/s0140 $\underline{-6736(20) 30460-8}$

Dennen, V.P., Aubteen Darabi, A., \& Smith, L.J. (2007). InstructorLearner Interaction in Online Courses: The relative perceived importance of particular instructor actions on performance and satisfaction. Distance Education, 28(1), 65-79. https://doi.org/ $\underline{10.1080 / 01587910701305319}$

Duffy, J. (2020). 20 Tips for Working From Home (online). Available at: https://www.pcmag.com/news/get-organized-20-tips-forworking-from-home

Forbes Coaches Council (2018). Top 15 Tips To Effectively Manage Remote Employees. Available at: https://www.forbes.com/ sites/forbescoachescouncil/2018/05/30/top-15-tips-to-effectivelymanage-remote-employees/\#265df65e503c

Larson, B.Z., Vroman, S.R., \& Makarius, E.E. (2020). A Guide to Managing Your (Newly) Remote Workers. Available at: https://hbr.org/2020/03/a-guide-to-managing-your-newly-remot e-workers

Myrick, F., Caplan, W., Smitten, J., \& Rusk, K. (2011). Preceptor/mentor education: A world of possibilities through e-learning technology. Nurse Education Today, 31(3), 263-267. https://doi.org/10.1016/i.nedt.2010.10.026

Nulty, D.D. (2008). The adequacy of response rates to online and paper surveys: what can be done? Assessment \& Evaluation in Higher Education, 33(3), 301-314. https://doi.org/10.1080/ $\underline{02602930701293231}$
Rand, M.L., \& Pajarillo, E.J. (2015). A robust social and professional connection between master educator and Doctor of Nursing Practice (DNP) student instructor: Virtual mentoring and preceptorship via distance education. Nurse Education Today, 35(5), 696-699. https://doi.org/10.1016/j.nedt.2015.01.009

Rowe, M., Frantz, J., \& Bozalek, V. (2012). The role of blended learning in the clinical education of healthcare students: A systematic review. Medical Teacher, 34(4), 216-221. https://doi.org/10.3109/0142159X.2012.642831

The Government of Ontario (2020). Ontario Takes Further Action to Stop the Spread of COVID-19. Available at: https://news. ontario.ca/en/release/56642/ontario-takes-further-action-to-stop -the-spread-of-covid-19

\section{Appendix A}

\section{Survey Questions}

This survey is to gain insight on what the best practices are for conducting a remote experiential rotation from a student's perspective.

By completing the survey, you have given us consent to use your information for our study. All information will be kept confidential and will only be shared amongst the study team. No personal information will be collected. By completing the survey, you will give us better insight on how remote experiential rotations should be held in the future. There are no risks or harms associated with this study. Withdrawal of consent may occur at any point of the study.

If you have any questions or concerns, feel free to contact Catherine Zhu at cat.zhu@mail.utoronto.ca.

1. What is your sex?

$$
\begin{array}{ll} 
& \text { Female } \\
\mathrm{O} & \text { Male } \\
\mathrm{O} & \text { Prefer not to say } \\
& \text { Other: }
\end{array}
$$

2. How many virtual rotations have you completed up to this point?

$$
\begin{array}{ll}
\bigcirc & 1 \\
0 & 2
\end{array}
$$$$
\text { ○ } 3
$$

3. Type of rotation(s). Check all that apply

$$
\begin{aligned}
& \square \text { Education } \\
& \square \text { Research } \\
& \square \text { Industry } \\
& \square \text { Other: }
\end{aligned}
$$

4. Have you had an in-person experiential rotation with a preceptor before (i.e. EPE)?

$$
\begin{array}{ll}
\mathrm{O} & \text { Yes } \\
\mathrm{O} & \text { No }
\end{array}
$$

5. My preceptor set expectations at the beginning of my rotation.

O Yes (if yes, go to question 6)

No (if no, go to question 7) 
6. If yes, my preceptor and I set expectations collaboratively
$\bigcirc$ Yes

O No

7. If no, why were expectations not set at the beginning Free form answer

8. The expectations set were clear from the beginning of my rotation(s).
O 1. Strongly disagree
2. Disagree
O 3. Neutral
O 4. Agree
- 5. Strongly disagree

9. I used the following modes of communication with my preceptor (check all that apply):

$\square$ Video conferencing (i.e. Zoom, Skype, Microsoft Teams)

$\square$ E-mail

$\square$ Text message

$\square$ Phone call

$\square$ Other:

10. If you used video conferencing platform, which one did you use? Check all that apply.
$\square$ Zoom
$\square$ Skype
$\square$ Microsoft Teams
$\square$ Bb Collaborate
$\square$ Facetime
$\square$ Other:

11. The mode(s) of communication I used with my preceptor was/were adequate and easy to navigate.
○ 1. Strongly disagree
○ 2. Disagree
3. Neutral
4. Agree
5. Strongly disagree

12. My preceptor and I had set meeting times through a video conferencing platform or phone call.
Y Yes
O No

13. My preceptor and I had many impromptu meeting times through a video conferencing platform or phone call.
O Never
- 1-2 times between meetings
O 3-5 times between meetings
Other:

14. How often did you and your preceptor meet on a scheduled basis?

$\begin{array}{ll}\bigcirc & \text { More than once daily } \\ \bigcirc & \text { Once daily } \\ \bigcirc & \text { Few times weekly } \\ \bigcirc & \text { Once weekly } \\ \bigcirc & \text { Other: }\end{array}$

15. The frequency of our meetings was sufficient to keep me on track to complete my assigned work.
$\bigcirc \quad$ Wanted less meetings
No change
O Wanted more meetings

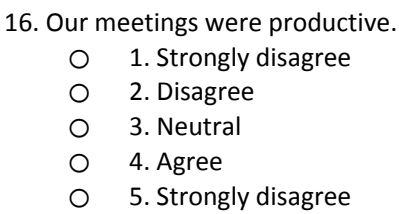

17. I felt comfortable communicating any issues I had with my assigned work to my preceptor.
O 1. Strongly disagree
2. Disagree
3. Neutral
4. Agree
5. Strongly disagree

18. My preceptor provided me with ongoing feedback and constructive criticism.
O 1. Strongly disagree
2. Disagree
3. Neutral
4. Agree
5. Strongly disagree

19. Is there anything your preceptor could have improved on regarding communication?

Free form answer

20. My preceptor made an effort to get to know me.
O 1. Strongly disagree
2. Disagree
O 3. Neutral
4. Agree
O 5. Strongly disagree

21. I had a good relationship with my preceptor.
○ 1. Strongly disagree
2. Disagree
3. Neutral
4. Agree
5. Strongly disagree

22. I was able to build a similar rapport with my remote preceptor as with my in-person preceptor(s) in the past.
1. Strongly disagree
2. Disagree
3. Neutral
4. Agree
5. Strongly disagree

23. My preceptor was always available to answer any questions.
O 1. Strongly disagree
2. Disagree
3. Neutral
O 4. Agree
5. Strongly disagree

24. I had many competing priorities while completing my remote APPE rotation(s).
O 1. Strongly disagree
○ 2. Disagree
3. Neutral
○ 4. Agree
5. Strongly disagree 
25. I had more difficulty prioritising my work during my remote rotation(s) than during my in-person rotation(s).
$O$ 1. Strongly disagree
O 2. Disagree
O 3. Neutral
O 4. Agree
5. Strongly disagree

26. My preceptor allowed me to create my own hours and schedule.

Yes (if yes, go to question 27)

No

27. If you answered YES to the above question, rate the following statement: having flexibility to create my own hours and schedule was beneficial.
O 1. Strongly disagree
O 2. Disagree
3. Neutral
O 4. Agree
O 5. Strongly disagree

28. I was able to maintain a daily routine.
O 1. Strongly disagree
O 2. Disagree
3. Neutral
O 4. Agree
O 5. Strongly disagree

29. I had set hours, either set by preceptor or myself, during the day to complete my assigned work.
O Yes
O No

30. The resources I needed were easily accessible for me.
O 1. Strongly disagree
O 2. Disagree
O 3. Neutral
O 4. Agree
- 5. Strongly disagree

31. My Internet connection was adequate.
O 1. Strongly disagree
2. Disagree
3. Neutral
O 4. Agree
5. Strongly disagree

32. I was able to utilize appropriate IT support, if needed (i.e. from the Faculty, third party companies).
O 1. Strongly disagree
O 2. Disagree
3. Neutral
O 4. Agree
5. Strongly disagree

33. I was able to send documents to my preceptor.

$$
\begin{array}{ll} 
& \text { Yes (if yes, go to question } 34 \text { ) } \\
& \text { No }
\end{array}
$$

34. If you answered YES to the above question: which mode did you send your documents by? Check all that apply.

$\square$ E-mail

$\square$ Chat box through video conferencing system (i.e. Zoom, Microsoft Teams)

$\square$ Share screen through video conferencing system (i.e. Zoom, Microsoft Team) $\square$ Instant messaging (i.e. Slack, Google Hangouts)

$\square$ Other:

35. If you had any issues with sending documents, please explain these issues.

Free form response.

36. I had a comfortable work environment.
O 1. Strongly disagree
0 2. Disagree
O 3. Neutral
O 4. Agree
O 5. Strongly disagree

37. My work environment was free from any distractions.
O 1. Strongly disagree
- 2. Disagree
3. Neutral
O 4. Agree
5. Strongly disagree

38. Describe your work environment.

Free form answer.

39. My assigned work involved confidential information.

$\mathrm{O}$ Yes (if yes, go to question 40)

O No

40. If you answered YES to the above question, did your work environment allow you to maintain confidentiality (i.e. no one could hear you when you needed to say confidential information out loud).
O Yes
O No

41. I was highly motivated at the beginning of my APPE rotation(s).
O 1. Strongly disagree
2. Disagree
3. Neutra
O 4. Agree
O 5. Strongly disagree

42. I was highly motivated throughout my APPE rotation(s).
O 1. Strongly disagree
O 2. Disagree
O 3. Neutral
O 4. Agree
5. Strongly disagree

43. I felt a similar level of motivation during my remote rotation(s) than my previous in-person rotation(s).
O 1. Strongly disagree
2. Disagree
3. Neutral
O 4. Agree
5. Strongly disagree

44. What were the factors that contributed to your motivation during your remote APPE rotation(s)? Check all that apply.

$\square$ Set expectations

$\square$ Good communication with my preceptor

$\square$ Set meeting times with my preceptor

$\square$ Daily routine

$\square$ Set work hours

$\square$ Good relationship with my preceptor

$\square$ Comfortable work environment 

Preceptor availability
Abundant resources available
Stable Internet connection
Other:

45. What were the factors that reduced your motivation during your remote APPE rotation(s)? Check all that apply.
$\square$ Lack of expectations
$\square$ Mismatched expectations between my preceptor and myself
$\square$ Poor communication with my preceptor
$\square$ Infrequent meetings with my preceptor
$\square$ Lack of daily routine
$\square$ Lack of set work hours
$\square$ Poor relationship with my preceptor
$\square$ Uncomfortable work environment
$\square$ Lack of preceptor availability
$\square$ Lack of resources
$\square$ Poor Internet connection
$\square$ Other:

46. My remote rotation(s) was more stressful than my past in-person rotation(s).
O 1. Strongly disagree
2. Disagree
3. Neutral
4. Agree
O 5. Strongly disagree

47. Overall, my remote APPE rotation(s) was a successful learning opportunity.
1. Strongly disagree
O 2. Disagree
3. Neutral
- 4. Agree
5. Strongly disagree

48. Any comments on how your remote APPE rotation could improve?

Free form answer. 